\title{
An Ultra Low Powered Msp430 Microcontroller Based Control System for a Composting Process
}

\author{
Prof. Rahane S.B. \\ Assistant Professor \\ Department of Electronics Engineering \\ Amrutvahini Engineering \\ College,Sangamner,Dist : \\ Ahemadnagar, $\mathrm{MH}$,India.
}

\begin{abstract}
This work presents the design of an intelligent controller for a composting process. It is designed around Texas Instruments ultra low powered MSP430F1232 microcontroller chip, Cypress semiconductors CYWM6935 wireless module for establishing a RF link between the two MSP430 microcontrollers. Composting provides environmentally and economically sustainable solution for promoting organic farming. Our work is a small step in developing a low cost and efficient control system for a compost manufacturing process which can be applied by farmers to produce nutrient rich, high quality organic fertilizer.
\end{abstract}

\section{Categories and Subject Descriptors}

C.3 [Special-Purpose and Application-Based Systems]: Microprocessor/microcomputer applications, Real time and embedded systems, process control.

\section{General Terms}

Measurement, Design, Experimentation, Verification.

\section{Keywords}

Microcontroller, composting, transmitter, receiver.

\section{INTRODUCTION}

Composting is a process by which organic material such as yard trimmings, kitchen scraps, wood shavings, cardboard, and paper is biodegraded by microorganisms, resulting in the production of organic and/or inorganic by-products and energy in the form of heat. Microorganisms that are normally present in organic waste materials, start the decomposition process when they are exposed to air, and the moisture content of the waste is brought to a suitable level; carbon dioxide, water and heat are given off. As a result the temperature of the heap rises thereby speeding up the basic degradation process, which normally occurs slowly in organic waste. The final product is a compost which is of significant value in agriculture. Moreover for the process to give significantly good quality compost the process parameters have to be properly monitored and adjusted. Two such parameters that are important and interdependent to some extent are temperature and oxygen content of the waste material[8]. So a control system is designed to control temperature of the composting process and air flow rate (oxygen supply).

\section{CONTROL SYSTEM DESIGN}

Control system is designed around a Texas Instrument's ultra low powered MSP430F1232 microcontroller,CYWM6935 wireless module for transmitting compost temperature to a remote monitoring station. Figure 1 shows the control scheme along with the compost reactor.

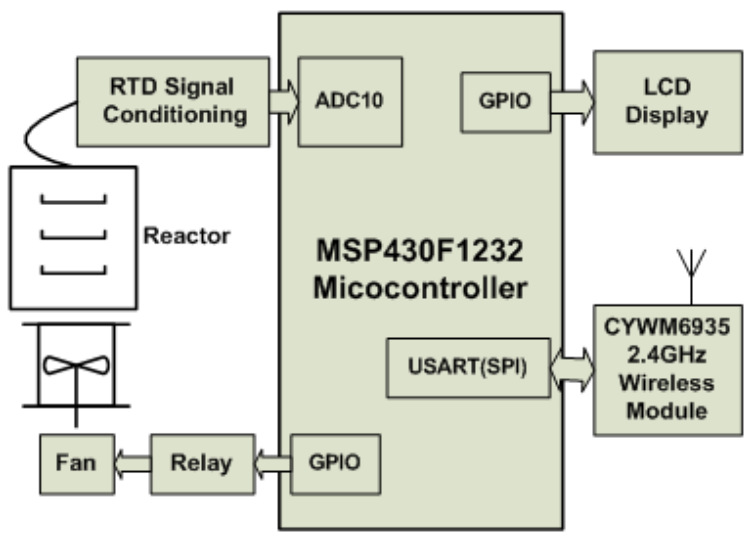

Figure 1. Compost Controller and Transmitter

Compost reactor consists of a drum that is insulated within an outer drum to prevent heat loss during the composting process. In the center of the inner drum, a resistance temperature detector(RTD), installed vertically, senses the temperature of the compost. A perforated plate, located approximately 5 inches above the bottom of the reactor, suspends the compost over the air inlet and provides even air distribution to the compost. Air flow to the compost is provided by the blower/fan. The fan offers a very easy means to introduce air(oxygen) in the reactor at regular intervals, and to circulate an air current to cool the process when required. There are basically two conditions for the fan to be switched on; whether the recorded temperature is above 55 degree $\mathrm{C}$, and at regular intervals of 20 minutes. In the first case the fan remains on as long as temperature does not fall below 55 degree C. In the second case the fan is switched on for approximately 30 seconds to allow an influx of oxygen required for the composting process. This amount of time is sufficient to allow enough oxygen in the plant for the process to be sustained [8].The moisture 
content of the compost mixture is adjusted by adding water to the compost reactors through the top sample ports.

\subsection{Signal Conditioning and Transmitter}

This application uses PT100 RTD for temperature sensing. The RTD signal conditioning circuit converts the resistance changes on account of temperature variations into a proportional voltage that is applied to analog to digital converter. The MSP430F1232 device integrate,10-bit $200 \mathrm{ksps}$ ADC with internal reference, sample and hold and data transfer controller. Also the USART configured in SPI mode is used to communicate with the CYWM6935 (2.4GHz ISM band)wireless module. The MSP430F1232 microcontroller acts as a SPI master while CYWM6935 wireless module acts as SPI slave. The acquired temperature information is processed according to the control logic , displayed locally on the LCD screen and simultaneously transmitted over the air using CYWM6935 module. Depending upon the time elapsed and temperature value the fan is switched on and off according to the logic depicted in the flowcharts.

The fan aerates and cools the compost in a reactor. The bacteria in the material require a minimum level of oxygen for their metabolic processes; they generate significant amounts of heat as they digest the compost. If left uncontrolled, they might use up all the oxygen or the temperature might rise to a level that would kill the bacteria.

\subsection{Remote Monitoring Station (Receiver)}

The remote monitoring station as shown in Figure 2 consists of MSP430F1232 microcontroller at it's heart,CYWM6935 wireless module and LCD display for remote monitoring of the compost temperature. The remote monitoring station can be placed at a centralized location to monitor the progress of the composting process. The CYWM6935 provides a complete SPI-to-antenna radio modem. The CYWM6935 is designed to implement wireless devices operating in the worldwide 2.4-GHz Industrial, Scientific, and Medical (ISM) frequency band $(2.4 \mathrm{GHz}$ to 2.4835 $\mathrm{GHz}$ )supporting a range of 50 meters or more. This restricts us to place remote monitoring station within 50 meters of the transmitter.

A Texas Instruments MSP430 Family microcontroller(MSP430F1232) has been chosen to use for the application because it is readily available, well supported with documentation and applications information, and has relatively inexpensive evaluation tools. The family of microcontrollers is designed specifically for industrial control, instrumentation, and measurement tasks with low-power, extended battery-life applications as prime design objectives[2][4]. Rather, the easy-tounderstand architecture, instruction set, and family structure contributed significantly to the selection.

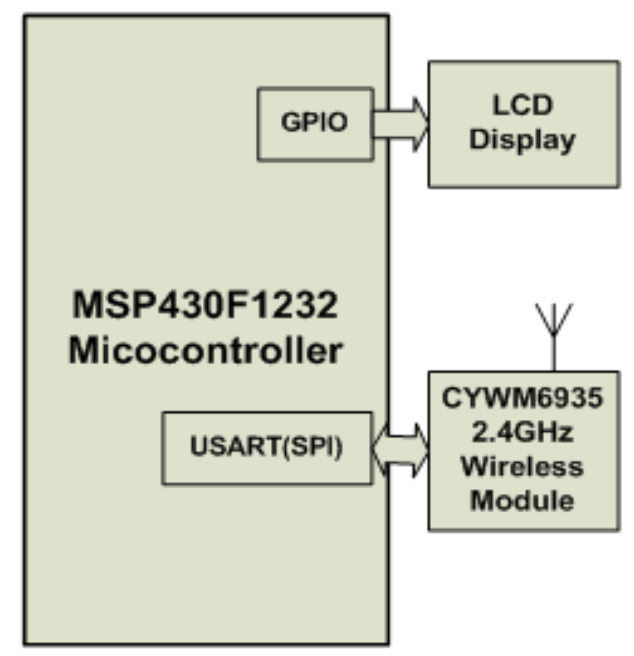

Figure 2. Remote Monitoring Station

\subsection{Flowcharts}
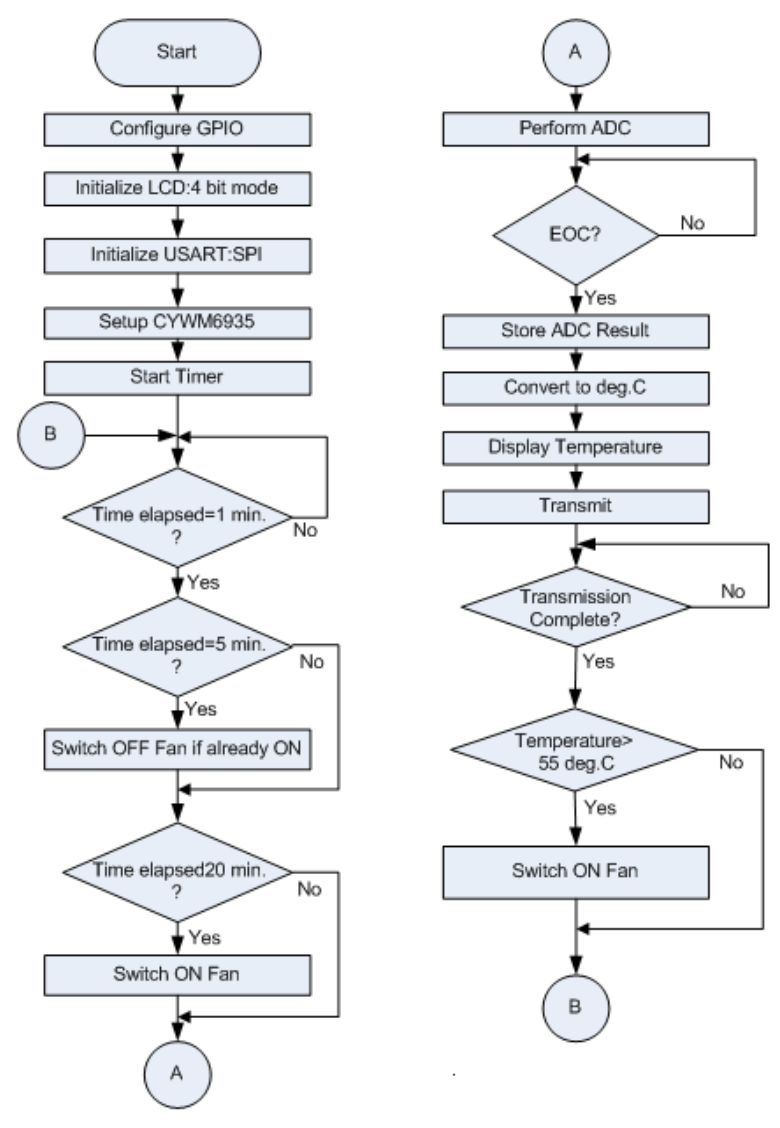

Figure 3. Transmitter Flowchart 


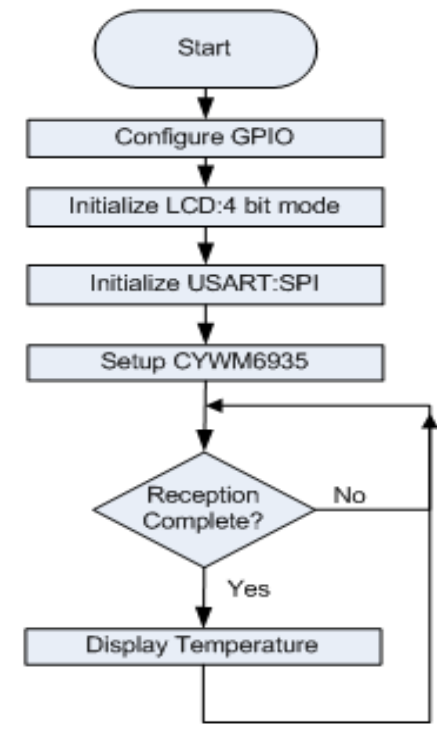

Figure 4. Receiver Flowchart

\section{SOFTWARE DEVELOPMENT}

The software for this application is developed in $\mathrm{C}$ language using the IAR Embedded Workbench IDE which contains MSP430 IAR C Compiler,MSP430 IAR assembler, a powerful editor, project manager and Flash Emulation Tool (FET) debugger. The complete development system comprising a PC with the IAR Embedded Workbench installed, Olimex FET connected to the PC parallel port, JTAG and target board are shown in Figure 5 .

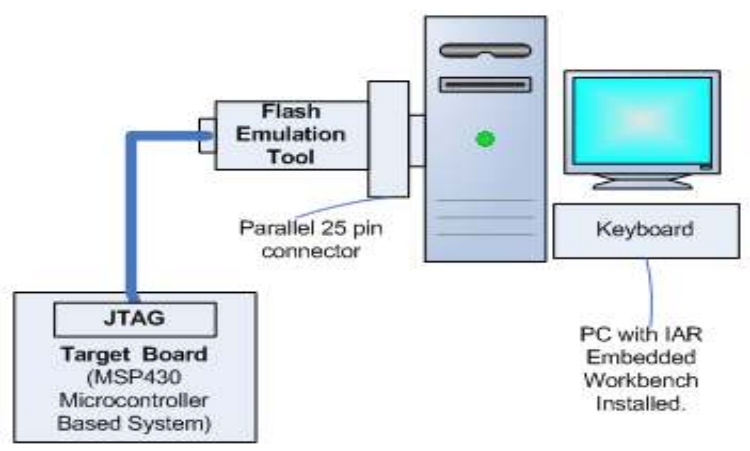

Figure 5. Software Development System

\section{SOLAR POWERED AND BATTERY OPERATED SYSTEM}

The entire electronics for this system is battery operated and solar powered. Solar panels charge the batteries. Power supply for the electronics uses low dropout regulators (LDOs) while the fan is driven by an inverter. So a solar powered control system for a environment friendly composting process makes this a truly green technology.

\section{CONCLUSION}

A control system for turning organic waste into a valuable product is presented in this paper. Usage of advanced microcontroller like Texas Instruments MSP430 makes the electronics reliable and ultra low powered. Composting reduces difficulty in treating organic waste and creates economic revenue stream from the sale of compost. It is a good source of fertilizer to the agricultural community for crop application. Applying a process control system ensures a product with consistent quality.

\section{REFERENCES}

[1] Cebrian, A., Rey, J., Tomos, A., and Millet, J .2005. Adapting power consumption to performance requirements in a MSP430 microcontroller . IEEE Conference on Electron Devices,2-4 Feb. 2005 p:83-86.

[2] Chris Nagy. Embedded System Design Using the TI MSP430 Series.Elsevier:Newnes publications,Burlington, MA 01803, USA,2003.

[3] Guide to Developing a Process Control System for a Composting Facility,Recycled Organics Unit,-2003 Second Edition,The University of New South Wales,Sydney, Australia.

[4] Jerry Luecke. Analog and Digital Circuits for Electronic Control System Applications ,Using the TI MSP430 Microcontroller. Elsevier:Newnes publications, Burlington, MA 01803, USA ,2005.

[5] MacGregor, S. T., Miller, F. C., Psarianos, K. M., and Finstein, M. S. 1981 . Composting Process Control Based on Interaction Between Microbial Heat Output and Temperature. Applied And Environmental Microbiology. June 1981, p. 1321-1330,Vol. 41, No. 6

[6] Neupane, U., Richie, S.M. and Weeks, A.R. 2005. Characterization of a low power, short range wireless transceiver. IEEE/ACES International Conference on Wireless Communications and Applied Computational Electromagnetics,3-7 April 2005 p.1041-1044.

[7] Nora Goldstein. 2006. Knowledge is Power in Compost Process Control. BioCycle, June 2006, Vol. 47, No. 6, p. 36.

[8] Oulun, M. K. , Jahmeerbacus, M. I., Soujaudah , K. M. S., Bhurtun, C. 2002 A Microcontroller Based Intelligent Controller For a Composting Plant. IEEE Africon,2-4 Oct. 2002 p. $101-104$ vol.1

[9] Scott Inglis,Peter Wright,Curt Gooch.Computerized Control System for Static Pile Composting of Dairy Manure. American Society of Agricultural Engineers (ASAE) Meeting Presentation,Paper Number: 024140. 